\title{
AN 'ALTERNATIVE’ MODEL TO ESTIMATE SOLAR RADIATION
}

\author{
T S G PEIRIS and R O THATTIL ${ }^{1}$
}

Coconut Research Institute, Lunuwila, Sri Lanka.

\begin{abstract}
Solar radiation is extremely useful in modelling many agricultural applications, but is hardly used due to the difficulty in obtaining data, and the time consuming process in estimating it by the Angstrōm (1924) formuls which uses world geographical relationships. To estimate solar radiation at the Coconut Research Institute, Lunuwila ( ${ }^{\circ} 20^{\prime} \mathrm{N} ; 7^{\circ} 53^{\prime}$ $\mathrm{E} ; 30.5 \mathrm{~m}$ ) an alternative model was developed frōm measured sunshine hours data only. The model had good fit $\left(R^{2}=0.90, P<0.001\right)$ and was found to have agreement with the estimates obtained from the Angstrōm model. The alternative model is more flexible and useful in estimating crop evapotranspiration, and for crop-weather modelling. The mean daily solar radiation at Lunuwila was estimated to be $18.3 \mathrm{MJ} \mathrm{m}^{-2} \mathrm{~d}^{-1}$ and the total annual solar radiation receipts is $6680 \mathrm{MJ} \mathrm{m}^{-2}(66.8 \mathrm{TJ}$ ha-1). The monthly solar radiation was highest in March (21.7 $\mathrm{MJ} \mathrm{m}^{-2} \mathrm{~d}^{-1}$ ) and the estimated 75\% probability value was 22.5 . June had the lowest (16.1 $\left.\mathrm{MJ} \mathrm{m}^{-2} \mathrm{~d}^{-1}\right)$ value and the estimated $75 \%$ probability value was 17.8 .
\end{abstract}

\section{INTRODUCTION}

The amount of radiation received at the higher level of the atmosphere is known as extra-terrestrial radiation ( $\left.R_{2}\right)$ and is dependent on latitude and the time of the year. Part of extra-terrestrial radiation is absorbed and scattered when passing through the atmosphere. The unabsorbed and a certain part of scattered rays reaching the earth's surface is called the incoming Solar radiation $\left(R_{2}\right)$. The amount of incoming solar radiation received effectively by the crop canopy after losses due to reflection, is the net short wave radiation $\left(R_{\mathrm{r}}\right)$ (Doorenbos and Pruitt, 1977). The $R_{\mathrm{w}}$ depends on the canopy reflection coefficient, but in

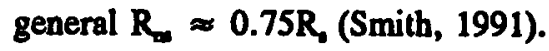

In the more advanced agro-meteorological stations Solar radiation is measured using various radiometers and pyranometers. In manual agro-meteorological stations it is measured using actinograph and solarimeters. However, measured solar radiation data are not available from many agro-meteorological stations. The reasons for the shortage of such data are due to complexity and cost of apparatus, and the work connected with the careful calibration and maintenance of instruments (Smith, 1991). Further, Stanhill (1965) showed that the estimation of solar radiation, using the Angström formula is more accurate than the measurements taken from actinograph.

\section{Department of Crop Science, University of Peradeniya, Sri Lanka.}


Solar radiation is very important in physiological processes of crops as it is the source of energy for photosynthesis. The data on solar radiation are useful for determining the irrigation water requirements for crops. The importance of solar radiation on coconut was recently highlighted by several authors. Foale (1993) estimated that if a coconut canopy intercepts all the incoming solar radiation and the canopy operates at maximum light use efficiency (about $20.5 \mathrm{MJ} \mathrm{m}^{-2} \mathrm{~d}^{-4}$ ), coconut palms would be able to produce $51 \mathrm{t} / \mathrm{ha} /$ year of dry matter. Panabokke (1994) suggested that solar radiation could be used for land suitability assessment of coconut growing areas. However, detailed studies on the impact of solar radiation on coconut have not been carried out mainly due to non availability of such data (Peiris, et al., 1995).

In view of the above, a linear regression model was developed to estimate monthlymean-daily solar radiation using the easily available climatic variable viz. duration of sunshine hours alone. The distribution of solar radiation at the Coconut Research Institute (CRI) is also discussed.

\section{MATERIALS AND METHODS}

\section{Data}

The data on duration of sunshine hours from 1976 to 1992 at the CRI, Lunuwila (Latitude $7020^{\prime} \mathrm{N}$; Longitude $71^{\circ} 53^{\prime} \mathrm{E}$ and Altitude $30.5 \mathrm{~m}$ ) were used in this study. The sunshine duration was recorded daily at $15: 30 \mathrm{hrs}$ using the Campbell-stokes sunshine recorder at the agro-meteorological stations maintained by the Biometry division of the CRI.

\section{Statistical Modelling}

Solar radiation in a given day was estimated from the Angström formula, $\mathbf{R}_{\mathrm{a}}=\mathbf{a}+$ $b *(n / N)\}^{*} R$ developed in 1924 (Doorenbos and Pruitt, 1977), where a and $b$ are location specific coefficients referred to as fractions of extra terrestrial radiation on overcast days and on average days respectively. The values $n$ and $\mathbf{N}$ are the actual and maximum possible sunshine duration in a day respectively. This method is difficult and time consuming (Donk, van S J. et al, 1988). Many authors (Fritz and MacDonald, 1949; Black et al., 1954; Mateer, 1955; Stanhill, 1962; Chia, 1969; Samuel, 1991) established the values of a and b for different sites. Of them Samuel (1991) showed that for any location in Sri Lanka a = $0.14+1.20 *_{n} / \mathrm{N}-0.82 *(\mathrm{n} / \mathrm{N})^{2}$ and $\mathrm{b}=.1 .32-2.89 *_{n} / \mathrm{N}+2.24 *(\mathrm{n} / \mathrm{N})^{2}$.

Using Angström formula daily solar radiation values were computed for the period 1976 to 1992. The coefficients $a$ and $b$ were computed on daily basis using the above two equations. The $N$ (hrs) was estimated from $N=(24 / \pi) * \cos ^{-1}(-\tan \phi \tan \delta)$ where $\phi$ and $\delta$ are the declination and latitude of the location respectively (Smith, 1991). Using daily data the mean-monthly-daily solar radiation (SR) and the mean-monthly-daily sunshine duration (SS) were computed for the entire period.

For each year different models using SR as the dependant variable were estimated. The best 2 -variable model contained SS and mean-monthly-daily minimum air temperature (TMIN). However, the addition of a second variable did not significantly improve the $\mathbf{R}^{2}$ statistic. In all cases SS alone was sufficient to explain the model. 
As the graphical plot suggested parallel lines, in the next stage the hypothesis of parallelism (all lines having common slope) was tested using the reduction sums of squares principle. The lack of fit (LOF) test was performed using the statistic,

$$
F_{13}=\frac{\left(R S S_{1}-R S S_{3}\right) /\left(f_{1}-f_{3}\right)}{R S S_{3} / f_{3}} \sim F\left(f_{1}-f_{3}, f_{3}\right)
$$

where RSS $_{3}=$ Residual variation around separate regression lines, with d.f. $=f_{3}$ and RSS $_{1}=$ Residual variation around lines with a common slope, with d. $f_{0}=f_{l}$. The test was not significant at $\alpha=0.05\left(R S S_{1}=114.04, R S S_{3}=108.42, f_{1}=175\right.$ and $\left.f_{3}=160\right)$, and thus the lines can be assumed to have common slope. The obvious question that arises is, whether a common regression line can be used to model the relationship between SS and SR, irrespective of time. The hypothesis of a common line was tested using the statistic,

$$
F_{23}=\frac{\left(R S S_{2}-R S S_{3}\right) /\left(f_{2}-f_{3}\right)}{R S S_{3} / f_{3}} \sim F\left(f_{2}-f_{3}, f_{3}\right)
$$

where $\mathrm{RSS}_{2}=$ Residual variation around a common line, with d.f. $=\mathrm{f}_{2}$. The computed $\mathrm{F}_{2}$ value $\left(R S S_{2}=115.12\right.$ and $\left.f_{2}=190\right)$ was not significant at $\dot{\alpha}=0.05$. Therefore, a single line can be used for the relationship, irrespective of time. The common model is $S R=6.4851$ $+1.7009 * S S\left(R^{2}=0.90 ; P<0.001\right)$.

\section{Model Validation}

The model was tested by checking the residuals based on the Durbin-Watson d-statistic (SAS, 1987) and was found that there was no serial correlation in the residuals. It indicated that the residuals of the above model exhibited random scatter without any systematic pattern. It was also found that the studentized residuals were extremely low for each predicted value. The plots were drawn for the SR values computed with Angström model and alternative model for 16 years (1976 - 1991) and it was found that both values were similar. Finally the model was tested with the 1992 data set as an independent set and the above model was found to have good fit. Therefore, the mean monthly-daily solar radiation (in $\mathrm{MJ} \mathrm{m}^{-2} \mathrm{~d}^{-1}$ ) at CRI can be easily estimated using the alternative model. The plots of the estimated SR from both the Angström and the alternate model from 1977 to 1992 are given in Figures 1.1 to 1.16 respectively. These plots show the similarity between the values estimated from both models.

\section{Distribution of Solar Radiation}

Summary statistics of mean-monthly solar radiation $\left(\mathrm{MJ} \mathrm{m}^{-2} \mathrm{~d}^{-1}\right)$ at the CRI based on 17 years (1976-1992). data are given in Table 1. The statistics $Q_{1}$ and $Q_{3}$ in Table 1 represent the chance of a larger event occurring one and three years out of four years, respectively. The mean annual solar radiation during this period is $18.3 \mathrm{MJ} \mathrm{m}^{-2} \mathrm{~d}^{-1}$ and so the total annual solar radiation receipts is $6680 \mathrm{MJ} \mathrm{m}^{-2}\left(66.8 \mathrm{TJ} \mathrm{ha}^{-1}\right)$. The results show that mean daily solar radiation decreases from February to June and then remain virtually constant at $17 \mathrm{MJ}^{-2}$ $\mathrm{d}^{-1}$. The solar radiation at the CRI varies from around $16 \mathrm{MJ} \mathrm{m}^{-2} \mathrm{~d}^{-1}$ in June to $22 \mathrm{MJ} \mathrm{m}^{-2}$ $\mathrm{d}^{-1}$ in March. Though the solar radiation is low during the two peak periods of rain in May 
and November, it is not high during dry periods from July to August. A detailed study of the climate variability at the CRI using different weather parameters are reported in a companion paper.

Table 1. Summary statistics of Solar Radiation at the CRI $\left(M J m^{-2} d^{-1}\right)$

\begin{tabular}{lllll}
\hline Month & Mean & SD & $Q_{1}$ & $\mathbf{Q}_{3}$ \\
\hline January & 17.9 & 1.44 & 16.9 & 19.0 \\
February & 21.0 & 2.89 & 20.6 & 23.3 \\
March & 21.7 & 1.46 & 20.9 & 22.5 \\
April & 20.3 & 1.35 & 19.5 & 21.3 \\
May & 18.3 & 1.19 & 17.7 & 18.8 \\
June & 16.0 & 2.51 & 15.0 & 17.8 \\
July & 17.3 & 1.38 & 16.2 & 17.5 \\
August & 18.0 & 1.47 & 17.5 & 18.5 \\
September & 17.9 & 1.95 & 17.1 & 19.6 \\
October & 17.8 & 1.82 & 16.4 & 18.6 \\
November & 16.4 & 2.04 & 15.6 & 17.9 \\
December & 17.0 & 1.17 & 16.5 & 17.8 \\
Mean & 18.3 & 2.34 & 16.9 & 19.7 \\
\hline
\end{tabular}

(based on estimated values from 1976 to 1992.

SD: Standard deviation; $Q, 25 \%$ percentile; Q3: $75 \%$ percentile)

\section{CONCLUSION}

Solar radiation at the CRI can be easily estimated using the alternative model. Only sunshine hour records are required. The alternative model is extremely useful to agricultural scientists to estimate the amount of solar radiation received at the canopy of a crop. This is useful in estimating crop evapotranspiration. The alternative model can be easily used to estimate the missing values, when the instruments used for solar radiation measurements are out of order. The linear relationship between SR and SS suggests that it is not necessary to consider both solar radiation and sunshine duration in crop-weather modelling. However, similar models will have to be investigated for other locations in Sri Lanka. Estimation of solar radiation is also useful in the design and estimation of performance of solar heaters and solar hot water systems etc. which are being used in Sri Lanka (Samuel, 1991).

\section{ACKNOWLEDGEMENTS .}

We are grateful to Mr. D T Mathes, Head, Biometry Division and the staff. The shortened version of this paper was presented at the Annual sessions of the Sri Lanka Association for the Advancement of Science (SLAAS) in December, 1993.

\section{REFERENCES}

Angström, A. (1924). Solar and terrestrial radiation. Q.J. Royal Meteorol. Soc. 50, 121-126. 
Black, J. N., Bonython, C. W. and Prescott, J. A. (1954). Solar radiation and duration of sunshine. Q. J. Royal Meteorol. Soc., 80(344): 231 - 235.

Chia, L. S. (1969). Sunshine and solar radiation in Singapore. Meteorol. Mag. 98, 265.

Doorenbos, J. and Pruitt. W. O. (1977). FAO Irrigation and Drainage Paper-Guidelines for Predicting Crop Water Requirements. No. 24. Food and Agriculture Organization, Rome.

Donk, van S. J., Sivakumar, M. V. K. and Kanemasu, E. T. (1988). Estimation of Penman potential evaporation for the West African sahel with an IBM PC. Department report, Kansas State University, Manhattan, KS 66506 USA.

Foale, M. A. (1993). Physiological Basis for Yield in Coconut. Advances in Coconut Research and Development (Proceedings of the International Symposium), 181-189, (Eds. Nair, M. K., Khan, H. H., Gopalasundram, P. \& Bhaskkara Rao, E. V. V.). Oxford \& IBH Publishing Co. Pvt. Ltd., New Delhi, India.

Fritz, S. and MacDonald, T. H. (1949). Average solar radiation in the United States. Heating Ventilating, 46, 61-64.

Mateer, C. L. (1955) A preliminary estimate of the average insolation in Canada. Can. J. Agric. Sci. 35, 579-594.

Mota, da F. S., Beirsdorf, M. I. C. and Acosta, M. J. C. (1977). Estimates of solar radiation in Brazil. Agric. Meteorology, 18, 241-254.

Panabokke, C. R. (1994). Land suitability assessment of coconut growing lands in the coconut triangle. Coconut Bulletin, CRI, Sri Lanka, Vol. 9 (No 1/2), 1-4.

Peiris, T. S. G., Thattil, R. O. and Mahindapala, R. (1995). An analysis of the effect of climate and weather on coconut (Cocos nucifera), Experimental Agriculture, Vol 10 (in Press).

Samuel, T. D. M. A. (1991). Estimation of global radiation for Sri Lanka. Solar Energy $47(5), 333-337$.

SAS Institute Inc. (1987). SAS/STAT Guide for personal Computers. Version 6 Edition. Cary, NC:SAS Institute Inc.

Smith, M (1991). Report on the expert consultation on procedures for revision of FAO guidelines for prediction of for crop water requirements. FAO Rome.

Stanhill, G. (1962). Solar radiation in Israel. Bull. Res. Counc. Israel, G. 11, 33-41.

Stanhill, G., (1965). A comparison of four methods of estimating solar radiation. In Methodology of Plant Eco-Physiology. Proc. Montpelier Symp., UNESCO, Paris, 55-61 pp. 

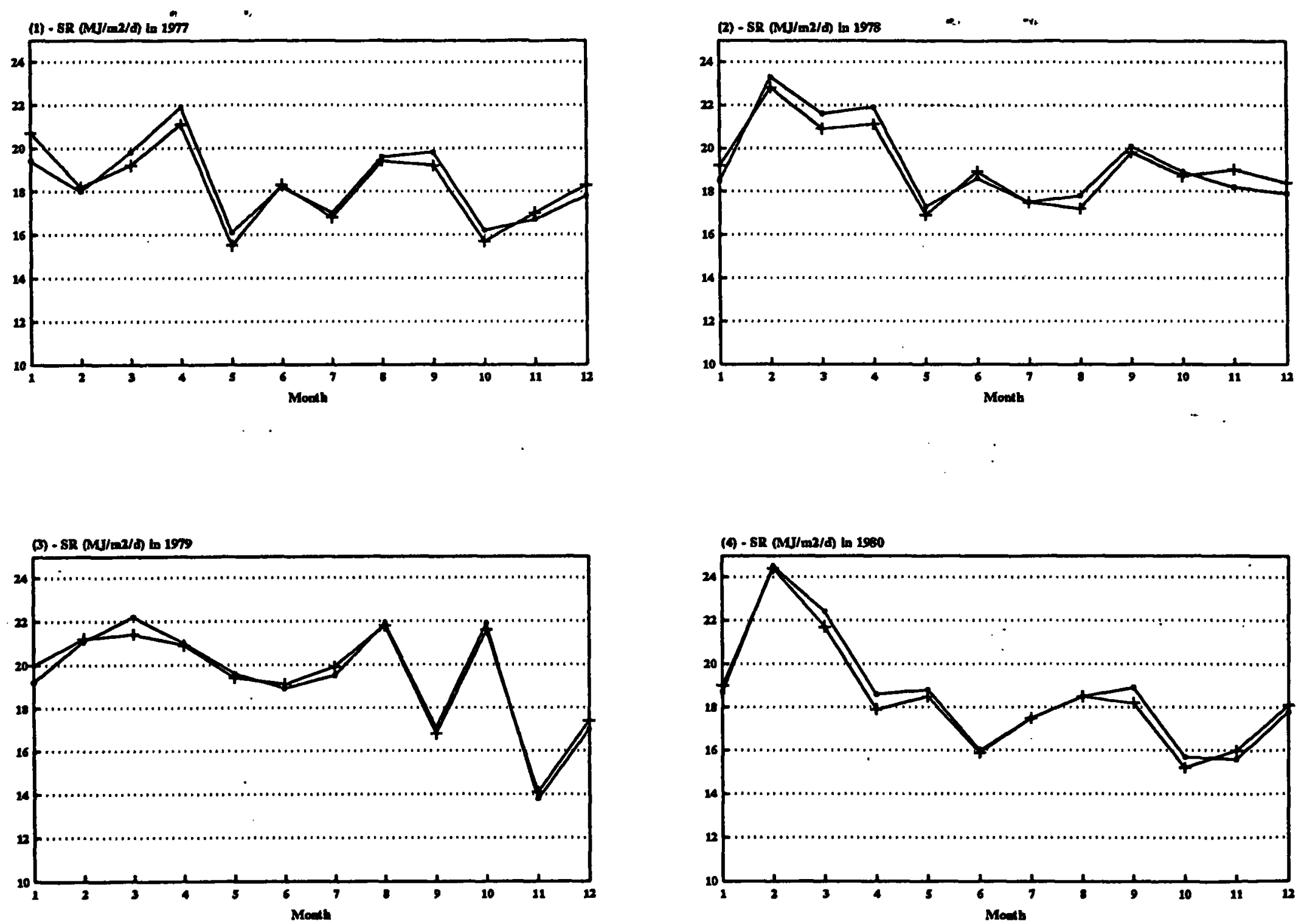

Figure 1 Estimated values of solar radiation (SR) at the CRI usiug Angstrom (.) and alternative (+) methods 

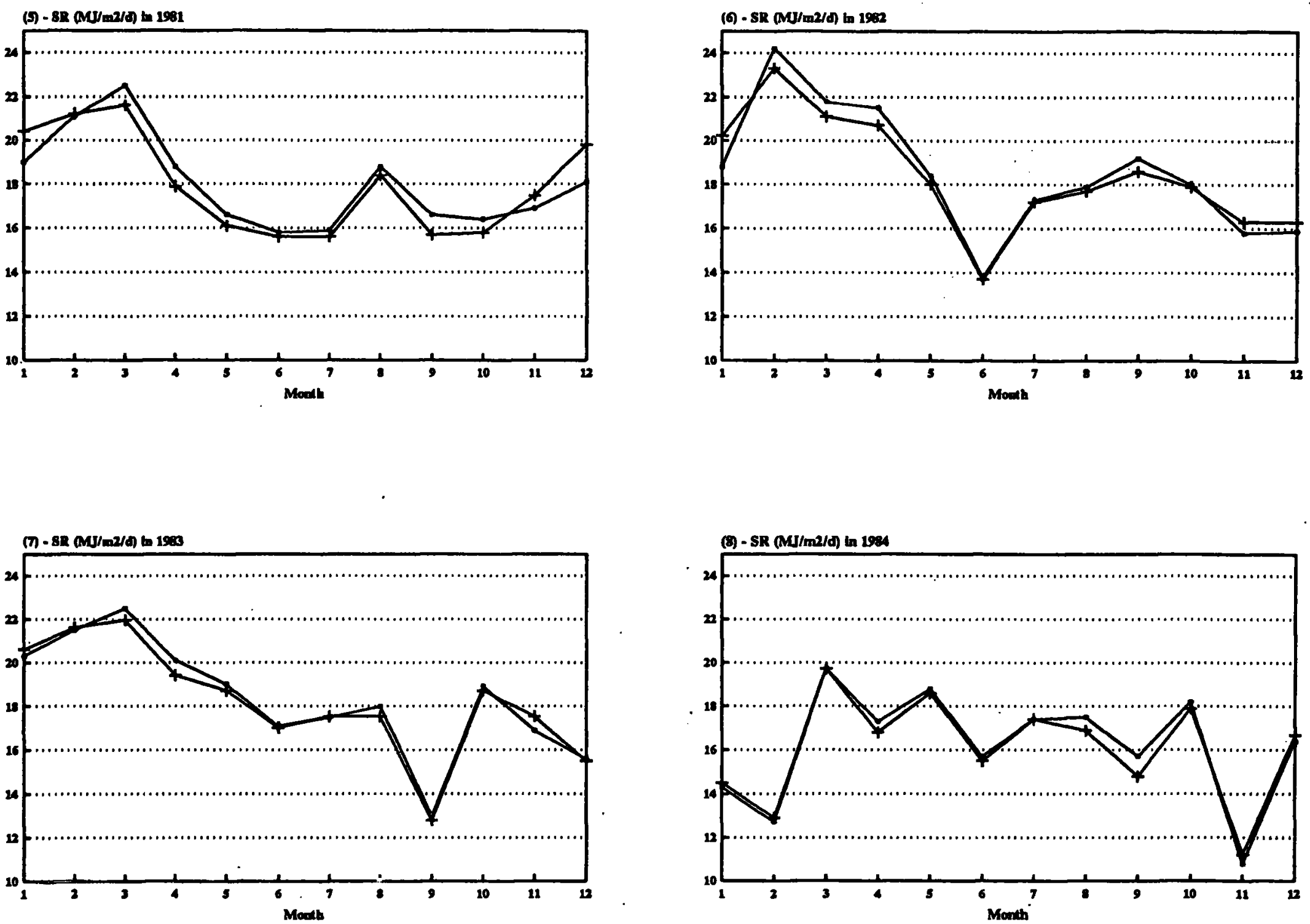

Figure 1 (Contd.) . 

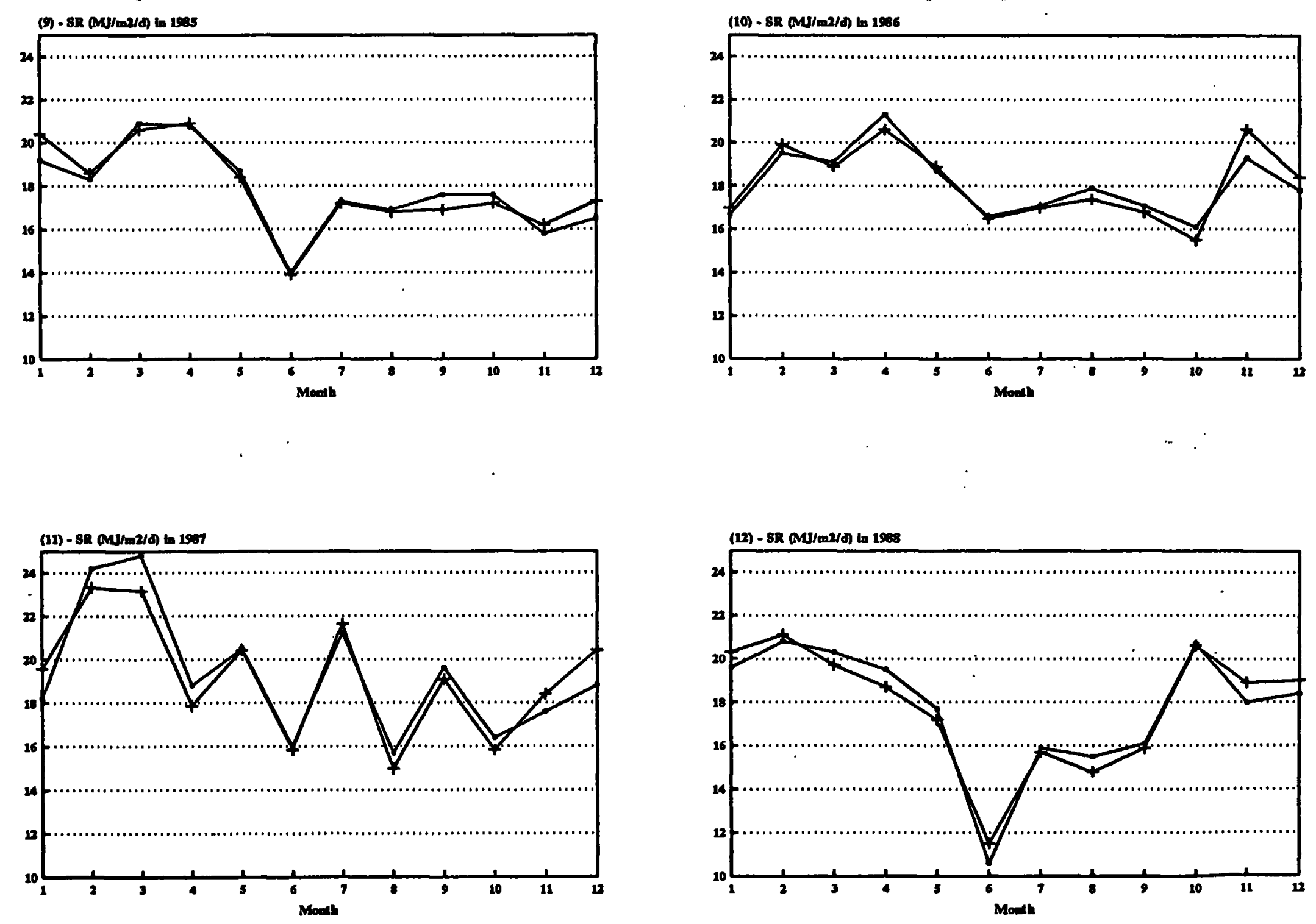

Figure 1 (Contd.) 
(13) - SR (MJ/m2/a) th 1939

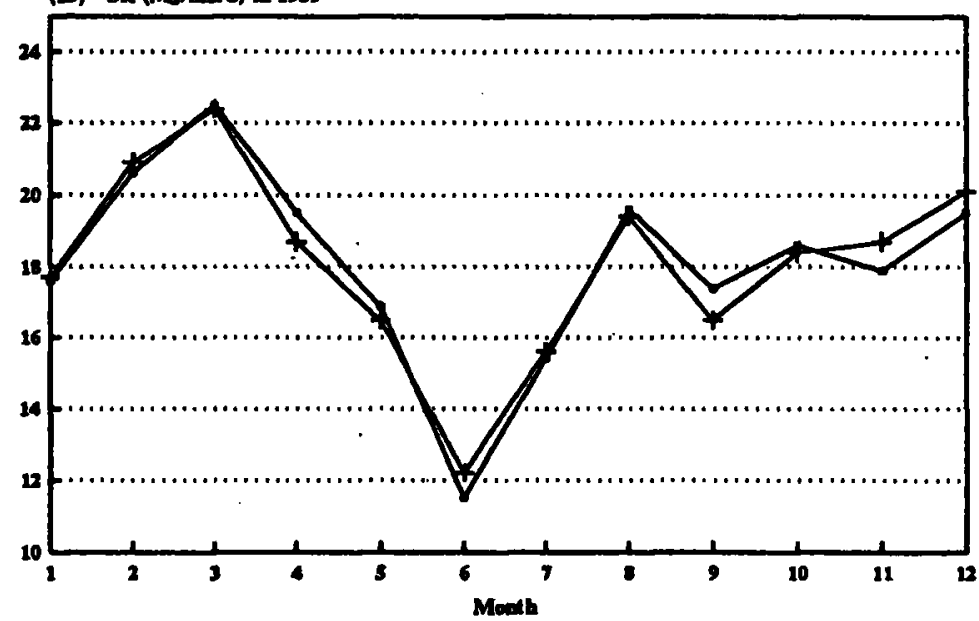

(1S) - SR $\left(M / \mathrm{mon}_{2} / \mathrm{d}\right.$ ) th 199

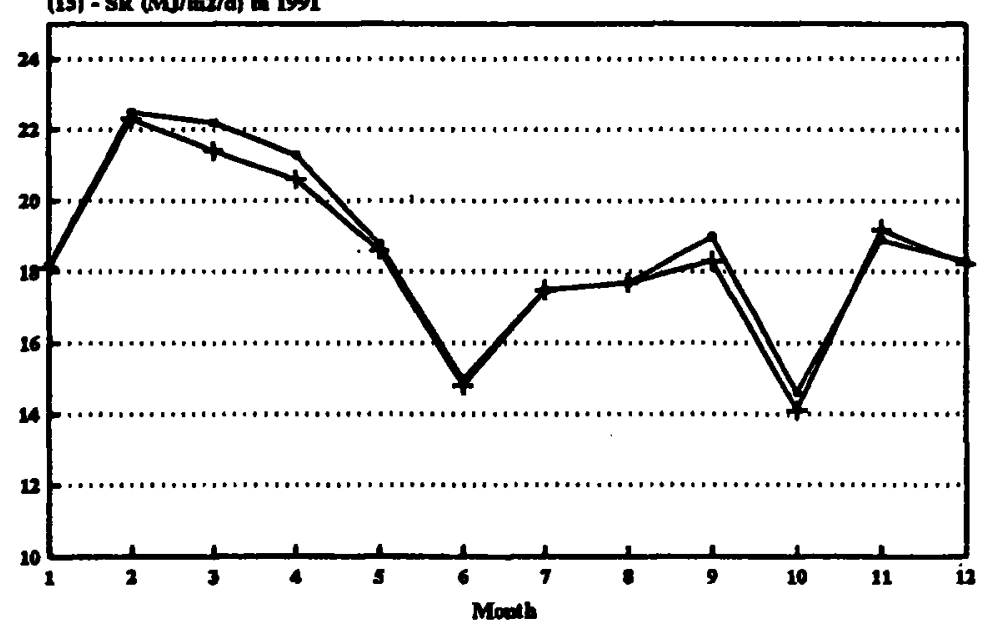

Figure 1 (Contd.2
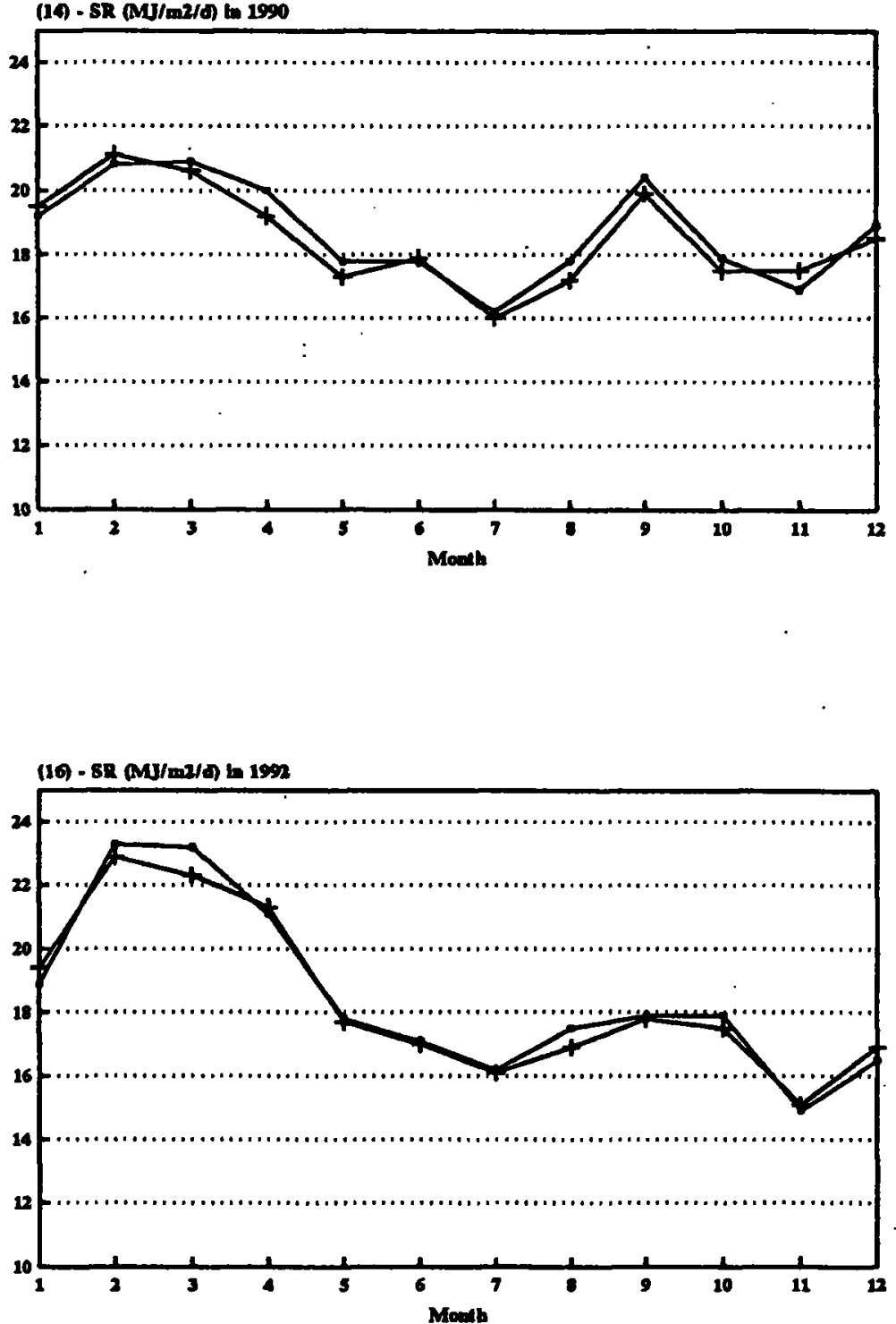